\title{
AVRUPA ANAYASASI VE YETKİ DAĞILIMI
}

\section{Deniz ILGAZ*}

\section{$\ddot{O z e t}{ }^{* *}$}

Avrupa Parlamentosu'nun geçiş başkanı Pat Cox tarafindan "Avrupa Birliği için çok önemli ve olumlu bir ileri adım" olarak nitelendirilen "Avrupa için bir Anayasa oluşturan Antlaşma," 17 - 18 Haziran 2004 tarihindeBrüksel'de gerçekleştirilen Zirve sonunda üzerinde uzlaşmaya varlldiktan ve 29 Ekim 2004 tarihinde Roma'da 25 üye ülke lideri tarafindan törenle imzalandıktan sonra yürürlüğe girebilmesi için üye ülkelerin kendi iç hukukları uyarınca kabul edilmesi sürecinin eşiğine gelmiştir. "Avrupa'nın Geleceği için Kurultay" kapsamında 16 aylık yoğun bir müzakere döneminin ardından Anayasa'nın yazılmasıyla ulaşılan bu noktada Avrupa'da ne gibi yeniliklere kapı aralanmıştır?

Son ana kadar süren tartışmalar arasında yer alan "Hıristiyanlık" kavramı Avrupa medeniyetinin dayandığı temellerden biri olarak kabul görmemiş, bunun yerine Avrupa'nın kültürel, dinî ve insanlı̆̆a değer veren mirasından esinlenilmiş olduğu ifadesi üzerinde fikir birliğine varllmıştır. Anayasa'nın belirlediği Avrupa Birliği değerleri, insan onuru, özgürlük, demokrasi, eşitlik, hukukun üstünlüğ̈̈ ve insan haklarına saygı olarak listelenmiştir. Azınlıklara ait olan kişilerin haklarına saygıya da vurgu yapan Anayasa, üye ülkelerdeki toplumların paylaştıkları ilkeler arasında çoğulculuk, ayrımcılı̆̆a karşı tavır, hoşgörü, adalet, dayanışma, kadın ve erkek arasında eşitliği saymıştır. AB'ye üyeliğin, Birliğin değerlerine ve bu değerleri diğer üye ülkelerle birlikte geleceğe taşımaya kararlı olan Avrupa ülkelerine açık olduğunun belirtilmesinin yanı sıra Anayasa'da ilk kez

*Yrd. Doç. Dr., Boğaziçi Üniversitesi, Yabancı Diller Yüksekokulu.

* For the summary in English, see the end page of the article. 
Birlik'ten çıkışla ilgili bir hüküm yer almaktadır. AB'nin temel değerlerini ciddi şekilde ihlâl edecek bir üye devletin üyeliği diğer üye devletlerin nitelikli çoğunluk oy ilkesine göre alacaklart bir kararla asklya alınabilecektir. Bír üye ülke kendi isteğiyle de Birlik'ten ayrtlabilecektir.

Birlik ile üye ülkeler arasında yetki paylaşımı konusunda üç yetki kategorisi saptanarak bunların kapsamları, içindeki politika alanları ile birlikte belirtilmektedir. Birliğe ait münhasır yetki, ortak ticaret politikası, gümrük birliği, euro'ya dahil olan ülkeler için para politikası gibi konularda Birliğin üye ülkeler üzerinde bağlayıcı karar alması anlamına gelmektedir. Paylaşılan yetki kategorisinde ise, iç pazar, içişleri, adalet ve güvenlik, tarım, balıkçılık, ulaştırma, enerji, sosyal ve çevre politikaları, tüketicinin korunması, kamu să̆lı̆̆ ile ilgili konular yer almakta; bunlarda Birlik, AB üye ülkeleriyle birlikte karar almaktadir. Üye ülkeler ekonomi ve istihdam politikalarını geliştirirken Birlik politikalarılala eşgüdüm sağlayacaklar, ortak savunma politikasını da kapsayacak şekilde ortak dı̧̧ ve güvenlik konularında Birlik bu politikayı belirleme ve uygulama yetkisine sahip olacaktır. Tamamlayıcı yetki kategorisinde ise, endüstri, sağllk, mesleki ve genel eğitim, gençlik, kültür, spor, turizm, sivil savunma, idarî işbirliği alanlarında Birlik, üye ülkelerin etkinliklerini koordine edecek, destekleyecek ve tamamlayacaktır.

\section{AB Anayasa Antlaşması'nın Genel bir İncelemesi}

Hassas dengeler üzerine oturan ve oluşumunu tam olarak sonuşlandırmamış olan Avrupa Birliği'nin Anayasası, 17 - 18 Haziran 2004 tarihinde Irlanda'nın Başkanlığında üye ülkelerin devlet ve hükümet başkanları tarafından Brüksel'deki zirvede onaylandı. ${ }^{1}$ Ardından, 29 Ekim 2004 günü Roma'da 25 üye ülkenin liderleri tarafından törenle imzalandı. Böylece, ikibinli yılların ilk on yılı içinde veya hemen sonrasında, ${ }^{2}$ her bir üye ülkenin Anayasa Antlaşmasını kendi iç hukukuna uygun bir biçimde kabulünden sonra yürürlüğe girebilmesinin yolu açılmış oldu. Birlik Anayasası, Topluluğun dört ayrı kurucu antlaşmasını ${ }^{3}$ ve bu antlaşmalan değiştiren ek antlaşmaları ${ }^{4}$ basitleştirerek ve yeniden düzenleyerek Anayasa metni altında toplamaktadır.

Dört bölümden ve Protokollerden oluşan Anayasa'nın Birinci Bölümü AB'nin değerlerini, hedeflerini, güçlerini tanımlamakta, yasama erkini nasıl kullanacağını ve hangi kurumlara sahip olacağını düzenlemekte, ayrıca Birliğin sembollerine, vatandaşlığına, demokratik yaşamına ve finans konularına yer vermektedir. "Üye Devletlerin ortak hedeflerine ulaşmak 
için yetkilerini devrettikleri” Birliğin, kendi değerlerine sayg1 gösteren ve bu değerleri birlikte geliştirmeye azmetmiş bütün Avrupa ülkelerine açık olacağı belirtilmektedir. İkinci Bölümde "Temel Haklar Bildirgesi," Üçüncü Bölümde ise ulusal anayasalardan farklı bir biçimde, iç ve dış ticaret de dahil olmak üzere, AB'nin bütün politika alanlan açıklanmaktadır. Genel ve Son hükümlerden oluşan Dördüncü Bölümde Anayasa'nın kabulü ve değiştirilmesiyle ilgili süreçlere de yer verilmektedir.

Birliğin sözü geçen değerleri nelerdir? İnsan onuruna ve hürriyetine, demokrasiye, eşitliğe, hukukun üstünlüğüne, insan haklarına ve azınlıklara mensup kişilerin haklarına duyulan saygıdır; toplumda çoğulculuğu, hoşgörüyü, adaleti, dayanışmayı desteklemek, ayrımcılığa karşı çıkmak, özellikle kadın ve erkek eşitliğini desteklemektir. Birlik, hedefleri arasında barışı geliştirmek, halkın iyiliği için uğraş vermek; yurttaşlarına iç sınırlanı olmayan bir özgürlük, güvenlik ve adalet alanı sağlamak; rekabetin serbest olduğu ve tahrif edilmediği bir Tek Pazar yaratmak gibi olumlu beklentileri saymaktadır.

Yeni bir hükümle, belirli sayıda üye ülke vatandaşı olan en az bir milyon kişinin imzasıyla sunulacak bir istekle Komisyon'u Konsey'e bir öneri sunma konusunda ikna edebilmenin de yolu açılmaktadır.

Hıristiyanlık kavramına Anayasa'da yer verilmemesi kararına uzun tartışmalardan sonra ulaşılmış, "din" sözcügüü Avrupa'daki bütün dinleri kucaklayacak bir biçimde Giriş (Dibace) sayfasında, kültür ve insanî değerlerle birlikte Avrupa'nın mirasını oluşturan değerler arasına eklenmiştir. Birliğin Demokratik Yaşamı başlıklı bölümünün altında, üye ülkelerde kabul gören ve uygulanan dinlere özgü ibadethanelerin ("churches") statïsüne ve diğer inançlara ya da dinî inançla ilgili olmayan amaçlara yönelik gruplaşmalara Birliğin saygı göstereceği ve aynımcılık yapmayacă̆ 1 belirtilmektedir.

Avrupa'nın sürdürülebilir kalkınması için çalışılırken dengeli bir ekonomik gelişme, sosyal pazar ekonomisi, tam istihdam ve sosyal gelişme göz önünde tutulacak, çevrenin niteliğinin korunması ve iyileştirilmesi çok yüksek bir hedef olarak benimsenecektir. İlimde ve teknolojide gelişmeler desteklenirken, sosyal dışlanmışlığa karşı savaş açılacak, sosyal adalet kapsamında kadın ve erkek eşitliğine, kuşaklar arasında dayanışmaya ve çocukların haklarının korunmasına çalışılacaktır. Üye Ülkeler arasında ekonomik, sosyal ve bölgesel bütünleşme ve dayanışma teşvik edilecektir. Zengin kültürel ve dilsel çeşitliliğiyle övünen ve buna saygı gösteren Birlik, 
Avrupa'nın ortak kültürel mirasının korunmasını ve desteklenmesini de garanti altına alacaktır.

Diş dünya ile ilişkilerde de Birlik, önem verdiği kendi değerlerini ve çıkarlanını savunmaya devam ederek, tüm dünyanın barıs, güven ve sürdürülebilir bir kalkınma içinde ilerlemeye, insanlar arasında dayanışma ve karşllıklı saygıya, serbest ve adil ticarete, yoksulluğun silinmesine ve insan haklarının korunmasına yönelik bir yol izleyerek, başta Birleşmiş Milletler Şartı olmak üzere uluslararası hukukun gözetimi ve gelişimi için çaba harcayacaktır.

Birlik, bütün bu hedeflere ulaşmak için Anayasa'nın her bir ilgili alanında kendisine bahşedilen yetkilere dayanarak hareket edecektir.

Birlik içinde, milliyetçiliğe dayanan herhangi bir ayrımcılık yasaklanırken, aynı zamanda her bir Üye Ülkenin ulusal kimliklerinin tanınacağ1; ülkelerin kendi bölgesel ve yerel yönetimleri de dahil olmak üzere temel siyasi ve anayasal yapılarına; toprak bütünlüğünü, hukuki düzeni ve iç güvenliği sağlayan tüm Devlet işlevlerine sayg1 gösterileceği vurgulanmaktadır.

Birliğin münhasır yetki sahibi olmadığı alanlarda da Birlik ve Üye Ülkeler, karşılıklı saygı temelinde, Anayasa'dan kaynaklanan bu hedeflere ilişkin görevleri üstlenmede birbirlerine yardımcı olacaklar ve hiçbir Üye Ülke Anayasa'nın öngördüğii bu hedeflere ulaşmada herhangi bir engel oluşturacak eylemlere girişmeyecektir.

Anayasa'nın İkinci Bölümü'nü Birlik üyesi ülkelerin vatandaşlarının ve bazı konularda Birlik içinde ikamet edenlerin veya bütün insanların haklarının tanındığı Temel Haklar Bildirgesi oluşturmaktadır. Dibaçesinde, "Avrupa'daki insan topluluklarının aralarında giderek daha yakın bir birlik" kurmakta olduklarından söz eden Bildirge'nin, Anayasa'nın diğer alanlarında yer alan bazı hükümlerle uyumlu olup olmadığı üzerine kuşkuların olmasının yanı sıra, Temel Haklar ve Yurttaşlık konusunda Birliğin İnsan Hakları ve Temel Özgürlükler Avrupa Sözleşmesi'ne ("Avrupa Sözleşmesi”) üye olarak katılma beklentisinin (ve de yeni eklemeyle, kararlılığının) ihtimal dahilinde olup olmadığı tartışılmaktadır. Birliğin, temel haklar konusunda Avrupa Sözleşmesi'nden ve Üye Ülkelerin anayasal geleneklerinde varolan ortak hükümlerden ilham alarak genel ilkelerini oluşturacağı belirtilse de, uygulamada Avrupa Birliği Adalet Divanı'nın (ATAD) temel haklar sözkonusu olduğunda kararlarında ortak 
pazarın işleyişi bağlamında ve Birliğin çıkarları doğrultusunda öngörülerde bulunarak ne Avrupa Sözleşmesi'ne ne de Üye Ülkelerin anayasa hükümlerine doğrudan bağlı kalmasının pek de mümkün olmayacağı görülmektedir. $^{5}$

Temel Haklar Bildirgesi, Birliğin kurumları ve organlan üzerinde etkili olacak; üye ülkeler üzerindeki bağlayıcı etkisi ancak üye ülkelerin Birlik hukukuyla düzenlenmiş politika alanlanndaki etkinlikleri üzerinde uygulanabilecektir. "Avrupa Sözleşmesi”nden daha geniş kapsamlı bir içeriğe sahip olan Bildirge, bio-etik ve kişisel veriler, işçilerin sosyal hakları, iyi yönetim hakkı gibi alanlara da genişletilmiştir. Bu konularda en son karar mercii olarak Avrupa Adalet Divanı (ATAD) yetkilendirilmiştir. Genel ilke şudur: Birliğin ya da üye ülkelerin taraf olduğu uluslararası antlaşmalar ve "Avrupa Sözleşmesi" ile çeliş̧i ortaya çıktığı durumlarda Bildirge, hangi belgede temel haklar daha geniş şekilde korunmaktaysa ona öncelik verecektir.

Birlik yurttaşlığının, Aynen Amsterdam Antlaşması'nda yer aldığı gibi, Taslak Anayasa Sözleşmesi'nde de Üye Ülkelerin vatandaşlarına özgü bir hak olacağı, fakat ulusal yurttaşlığın yerini almayarak, ulus yurttaşlığına ek olacağı belirtilmektedir.

Birlik Yurttaşlarının sahip olacağı haklar ve üstleneceği, görevler nelerdir? Bunlar şöyle sıralanmaktadır:

- Üye Ülkelerin topraklan içinde serbestçe dolaşmak ve ikamet etmek;

- İkamet ettikleri Üye Ülkede, Avrupa Parlamentosu seçimlerinde ve yerel belediye seçimlerinde, aynen ikamet ettikleri Üye Ülkenin vatandaşlanına uygulanan koşullar altında seçme ve seçilme hakkına sahip olmak. Burada gözden kaçırilmaması gereken bir husus, kendi ülkesi dışında bir Üye Ülkede ikamet eden bir AB yurttaşının, ikamet ettiği Üye Ülkenin genel seçimlerinde seçme ve seçilme hakkına sahip olmayacağıdır;

- Vatandaşı olduğu Üye Ülke'nin üçüncü bir ülkede diplomatik veya konsolosluk temsilciliği bulunmadığı durumda AB yurttaşlığı kişiye herhangi bir Üye Ülkenin sözü geçen üçüncü ülkede diplomatik veya konsolosluk yetkilileri tarafından aynen kendi yurttaşlarına tanıdığ koşullarda koruma sağlamasını kazandırmaktadır; 
- Avrupa Parlamentosu'na şikayette bulunmak; Avrupa Kamu Denetçisi'ne (Ombudsman) başvurmak; Birliğin kurumlarına ve danışma kuruluşlanna Anayasa'nın dillerinden herhangi birinde başvurmak ve aynı dilde yanıt almak.

\section{Yetkiler konusu: Kimin "Neyi" "Ne Kadar" Yapacağı}

Belçika'da Laeken'de “Avrupa'nın Geleceği Kurultayı"nın bir yıldan uzun bir sure yürütülmesinin somut bir ürünüi olarak ortaya çıkan Anayasa antlaşmasının yüzde onundan az bir kısmı üzerinde yapılan son değişikliklerle nihaî metne ulaşılmıştır. ${ }^{6}$ Metnin temel yapısı olduğu gibi korunarak, özellikle büyük bir titizlikle ele alınan yetki dağılımı konusunda ufak tefek rütuşlar dışında esas çatıya dokunulmamıştır. Birlik hukukunun iiye ülkelerin hukukuna üstünlüğü ("primacy") prensibinin vurgulandı̆̆ının bir işareti olarak daha önce Madde I-10'da yer alan hüküm biraz daha öne, Madde I-6'ya, Birliğin tüzel kişiliğini belirleyen Madde'nin önüne, "Birliğin Tanımı ve Hedefleri" başlıklı Birinci Kısmın içine alınmıştır. Hiç kuşkusuz Birliğin en karmaşık ve tartışmalı konusu olan yetki dağılımı, Anayasa içinde de birçok soru işareti uyandıracak bir biçimde yer almaktadır.

Avrupa Topluluğu'nun ve Birliği'nin 40 yılı aşkın süren yaşamı içinde resmî olduğu kadar gayri resmî yollarla gerçekleştirilmiş olan çeşitli değişim ve dönüşümler de zaten bu güne kadar yetki dağılımı konusunun hiç bir zaman kesin bir netlikle belirlenmemiş olmasından kaynaklanmıştır. $\mathrm{Bu}$ durum bir bakıma Birliğin yararına çalışmış̦tı denilebilir: Avrupa Ekonomik Topluluğu bu yoldan siyasî bir Birliğe dönüşebilmiş, demokratikleşme tartışma ve çabalarını gündeme getirmiş, bir tür "federasyon"a doğru göreceli olarak ilerlemeyi sağlamıştır.

Anayasa'da yetki dağılımı ilk kez sınıflandırılarak listelenmektedir; "gri" alanda bırakılan birçok konularla birlikte. Örneğin, ekonomi ve istihdam politikalarının olduğu kadar ortak dış ve güvenlik politikasının da hangi yetki sınıfına dahil edileceğinin bilinmemesi sonucunda bu konular ayr olarak ele alınmış̧ır. Anayasa'nın ilk metniyle son metni arasında yapılan bir değişiklikle, Birliğin üye ülkelerin ekonomi alanındaki girişimlerini koordine etmesi değil de, üye ülkelerin ekonomi politikalarını Birliğinkilerle koordine edeceklerinin altını çizen bir siyasi yoruma gidilmiştir. Birliğe düşen görev, ekonomi politikalarına yönelik geniş çerçeveli bir kılavuz oluşturmaktır. Benzer bir siyasi hassasiyet de araştırma ve teknolojik gelişme konularında öngörülen işbirliğinde ortaya 
çıkmış, bu konular da yüksek bir siyasi profil çizmek için "paylaşılan yetki alanları" içine alınmış olsalar da daha çok paralel olarak sürdürülecek bir yetki paylaşımı gibi algılanacak biçimde değiştirilmiştir.

Avrupa Birliği ile Üye Ülkeler arasındaki yetki dağılımında kimin "neyi" "ne kadar" yapacağı konusunda kuşkuya yer bırakmamak amacıyla konuları üç yetki grubu altında sınıflandırma yöntemi getirilmektedir. Anayasa'da, Birliğin kendisinin Üye Ülkelerce yetkilendirilmemiş olduğu alanlarda yasa yapmaya giriştiğine ya da bahşedilmiş yetkiyi aşarak ve ayrıntılara fazla girerek ölçüyü kaçırdığına dair endişe duyan kişilerin tepkilerine karş1 oluşturulan yetki paylaşımı kategorilerine göre listelenmiş konu başlıkları yer almaktadır. (Madde I - 11 - 17) Ayrica Anayasa, yetkilerin aşılması durumunda yerindenlik ("subsidiarity") ve orantılllık ("proportionality") ilkelerinin gözetilip gözetilmediğini denetleyecek mekanizmaların eksikliğini de göz önüne alarak bu konuda denetim işini ulusal parlamentolara birakacak bir sistem yaratmaktadır.

Yerindenlik ilkesi, kararların herhangi bir siyasi sistem içinde en etkin işleyebilecek sonuçların elde edileceği idarî düzeyde alınmasını öngörmektedir. Kararlar, elverdiğince yerel veya ulusal düzeylerde alınacak; ancak Birlik düzeyinde karar alınması en iyi sonucu vereceği durumlarda bu yola gidilecektir. İlk kez 1975 yılında Belçika Başbakanı Leo Tindesmans'ın yayımladığı bir raporda ortaya konulan bu kavram Avrupa'nın vatandaşlara daha yakın olacak bir entegrasyona gidebilmesini tasarlamaktaydı. Yerindenlik daha sonra Maastricht Antlaşması'nda yerini aldı. Yerindenlik ve orantılılık ilkeleriyle ilgili bir Protokol Amsterdam Antlaşması'na da eklendi. Orantılılık ilkesinin anlamı da, yerindenlik ilkesinin uygulanması durumunda Birliğin ancak ve ancak Antlaşma hedeflerine ulaşmayı gerektirecek oranda karar almak ve eylemlere girişmekle yetineceğinin altını çizmektedir.

Anayasa'da yer alan üç yetki kategorisinden birincisinde Birliğin uluslarüstii ("supranational") gücünü münhasıren kullanma durumunda olduğu konular (Madde I-13); ikinci grupta Birliğin Üye Ülkelerle paylaştığı yetkiler (Madde I - 14); üçüncüsünde ise Birliğin Üye Ülkeleri destekleme, tamamlama ve koordine etme yetkisinin bulunduğu konular gelmektedir (Madde I - 17). Bu kategorilerden aynı olarak Üye Ülkelerin, ekonomi politikalarını Birliğe göre koordine edecekleri belirtilmekte; istihdam konusunda ise Birliğe, Üye Ülkelerin politikalarını koordine etme yetkisi tanınmaktadır. (Madde I - 15) Birliğe bahşedilen daha da önemli bir yetki alanı, kısaca CFSP olarak bilinen "ortak dış ve güvenlik politikası"nı 
tanımlama ve uygulamaya koyma gücü ve görevi, ve buna ek olarak giderek gelişecek bir savunma politikasının çerçevesinin oluşturulmasıdır. $\mathrm{Bu}$ alanda Üye Ülkelere düşen, Birliğin atacağı adımları aktif ve çekincesiz bir biçimde, sadakat ve ortak dayanışma duyguları içinde desteklemek olacaktır. Üye Ülkeler ayrıca Birliğin çıkarına ters düşecek veya etkinliğine zarar verecek eylemlerden de sakınacaklardır. (Madde I - 16)

Anayasa'da Birliğe, kendisine Üye Ülkelerce resmen bahşedilmiş olan yetkileri gerektiğinde aşma olanağ tanıyan bir esneklik ("flexibility") hükmü de yer almaktadır. (Madde I - 18) Avrupa Topluluğu'nun Kurucu Anlaşması'nın Madde 308'ini çağrıştıran bu hüküm yalnızca ortak Pazar konularıyla sınırlı kalmayarak bütün politika alanlan için öngörülmektedir. Konsey'de oybirliğiyle karar alınması koşuluyla Avrupa Parlamentosu'nun onayını da gerektirecek bir sürece tabi kılınmıştır. Esneklik hükmü Komisyon'a da önemli bir görev yüklemektedir. Konsey'de esneklik hükmüne dayanılarak ele alınacak konular açısından Komisyon, üye ülkelerin parlamentolarını bilgilendirecek, böylece yerindenlik ve orantılılık ilkelerinin denetiminin sürdürülmesini sağlamaya çalışacaktır.

Anayasa yine de Birliği, kendisine tanınan yetki alanlarının sınırlarını kesin ve güçlü bir biçimde gözetmeye zorlamaktadır. Yetki devrinin ancak ve ancak Anayasa'daki hedefleri gerçekleştirmek için Birliğe bahşedilmiş olan alanlarla kısıtlı olacağı, Birliğin ancak bu alanlar içinde kalacağı, ve yetki devri yapılmamış alanların Üye Ülkelerin yetkisinde kaldığı açık ve net olarak belirtilmektedir. Yetkilerin kullanılması (Madde I-11) konusunda getirilen erken uyarı sistemiyle ulusal parlamentolar, Birlik' te yasama süreci sonuçlandırılmadan ince yerindenlik ve orantılılık ilkelerine ne derece sadik kalındığını denetleyebileceklerdir. (Protokol 3)

Avrupa Adalet Divanı (ATAD) kararlarında farklı yetki türlerinin varlığına daha önce değinilmiş olsa da Topluluk Anlaşmalarının hiç birinde yer almamış olan üç yetki grubuna göre politika alanlarının listelenmesi işi ilk kez Anayasa metninde gerçekleştirilmektedir. Gerçi bu listelemenin pratikte bir yararı olacağı söylenemez çünkü her bir konuda yetkilerin Birlik tarafından nasıl kullanılacağı, yasama sürecinin nasıl yürütüleceği, Anayasa'nın III. Bölümü'nde yer alan ayrı ayn politika alanlarındaki hükümlerde farklı ayrıntılarla düzenlenmektedir. 
ATAD'ın 1964 yılındaki ünlü Costa v ENEL davasıyla yasalaştırmış olduğu, Topluluk hukukunun Üye Ülke mevzuatı üzerindeki üstünlüğünü belirleyen çok önemli bir ilke de Anayasa'da ilk kez Topluluğun birincil Anlaşma hukuku düzeyinde yerini almaktadır. (Madde I - 6) Birliğe tanınmış olan yetki alanlarında yasa oluşturması ve yasaların uygulanması açısından söz konusu ilke Topluluğun Birlik olma yolundaki gelişmesine çok önemli katkı sağlamıştır.

Birliğin kurumlarının açıklandığı Başlık (Title) IV, 18-31 Maddelerinde Avrupa Parlamentosu, Avrupa Konseyi, Bakanlar Konseyi, Avrupa Komisyonu, Avrupa Komisyonu Başkanı ve Birliğin Dışişleri Bakanı, Adalet Divanı, Avrupa Merkez Bankası, Sayıştay, ve Birliğin danışma kuruluşları olan Bölgeler Komitesi, ve Ekonomik ve Sosyal Komite ile ilgili temel bilgiler aktarılmaktadır. AB üye devletlerin liderlerinden oluşan Avrupa Konseyi tarafından nitelikli çoğunluk oy ilkesiyle seçilecek bir Konsey Başkanı'nın iki kez tekrarlanabilecek iki buçuk yıllık süre için oturabileceği bir koltuğun yaratılmasının yanı sıra, Birliğin dış ilişkilerini, güvenlik ve savunma politikalarını yürütecek bir Dışişleri Bakanı makamı da oluşturulmaktadır. Yeni kurulan Dış İlişkiler Konseyi'ne de başkanlık edecek olan Dışişleri Bakanı, ayrıca Avrupa Komisyonu'nda İkinci Başkan görevini de üstlenecektir. Dışişleri Bakanı da üye ülkelerin liderleri tarafından nitelikli çoğunluk oy ilkesiyle seçilecektir.

Belirli konu başlıkları altında toplanan Bakanlar Konseylerine, üçer üye ülkeden oluşan gruplar 18 ay süreyle başkanlık yapacaklardır. Euro bölgesi maliye bakanları Konseyine ise yine iki buçuk yıl süreyle hizmet verecek bir başkan seçilecektir.

Anayasa'nın üye ülke liderlerince onayını geciktiren bir başka konu da yine oy sistemi olmuştur. AB' nin en hassas konularında kullanılacak olan çifte çoğunluk oy ilkesi hem üye ülkelerin hem de toplam nüfusun üzerine temellendirilmiştir. Bir karar alınması için en az 15 üye ülkenin oluşturacağı blokun, Birlik nüfusunun yüzde $65^{\prime}$ 'ini temsil etmesi gerekmektedir. Karar almayı engelleyecek azınlık ise AB'nin en az dört üye ülkesinden oluşmalı veya nitelikli çoğunluğa erişilmelidir.

Birliğin yetkilerinin hangi yasal çerçeve içinde uygulanacağına ilişkin Başlık (Title) V'te Birliğin yasama erkini ne gibi mekanizmalar aracılığıyla kullanacağı düzenlenmiştir. 
Birliğin her bir politika alanında ayrı ayrı uygulamalarının açıklandığı Üçüncü Bölüm'deki hükümlere gönderme yapılarak, yasamada "Avrupa Yasaları"ndan, "Avrupa Çerçeve Yasaları"ndan, “Avrupa Tüzükleri”nden, "Avrupa Kararları"ndan, “Tavsiyeleri”nden ve "Görüşleri”nden yararlanılacağı belirtilmektedir. Tümüyle bağlayıcı ve Üye Ülkelerde doğrudan etkili olacak olan Avrupa Yasaları genel anlamda uygulanacak temel yasal düzenlemeleri oluşturacaktır. Avrupa Çerçeve Yasaları ise hedefledikleri sonuç açısından yönetildiği Üye Ülkede bağlayıcı bir yasal mevzuat oluşturan, fakat uygulama biçimini Üye Ülkenin ulusal otoritelerine birakan yasa metinleridir.

Ortak dış ve güvenlik politikasının içinde yer alacak olan ortak güvenlik ve savunma politikasına gelince, bu politika Birliğe üye ülkelerin sivil ve askeri olanaklarından yararlanarak hareket etme kolaylığı sağlayacaktır. Bu olanaklar barışı koruma, çatışmaları önleme ve Birleşmiş Milletler Şartı ilkeleri uyarınca uluslararası güvenliği güçlendirici görevler üstlenme amacıyla Birlik dışındaki hedeflere yönelik olarak da kullanılabilecektir.

Bu tür işlemlerde yararlanılacak olanaklar Üye Ülkelerden sağlanacaktır. Üye Ülkeler, ortak güvenlik ve savunma politikasınınuygulanması için sivil ve askeri yeteneklerini Birliğin kullanımına sunacaklar, Bakanlar Konseyi'nce tanımlanan hedeflere katkıda bulunacaklardır. Üye Ülkeler bu amaçla kendi askeri yeteneklerini geliştirmeyi olanaklan elverdiğince üstleneceklerdir. Birlik içinde savunma sektörünün sınai ve teknolojik temelini güçlendirmek için gerekli önlemleri belirlemede, gerçekleştirmede ve uygulamada karşılaşılacak güçlükleri yenmek, Avrupa'nın yetenekleri ve silahlanmasıyla ilgili politikaların oluşturulmasında Bakanlar Konseyi'ne katkıda bulunmak amaciyla bir Avrupa Silahlanma, Araştırma ve Askeri Yetenekler Ajansı kurulması hedefi de Anayasa'da yer almaktadır.

Ortak güvenlik ve savunma politikası, giderek çerçevesi belirginleşecek olan planlanmış işbirliğini ("structured cooperation") de öngörmektedir. Planlanmış işbirliğine dahil olan bir üye ülkenin kendi toprakları üzerinde silahlı saldırıya uğraması durumunda işbirliğine dahil diğer üye ülkelerden yardım sağlanacak, bu tür dayanışmaya terör saldırıları ya da doğal afet olayları da eklenecektir. Güçlendirilmiş işbirliği (Madde I - 44) mekanizmasından yararlanan belirli sayıda üye ülkeler Birliğe bahşedilen bazı yetkileri kullanma hakkına sahip olmaktadırlar. Bu hükme göre, katılmaya gönüllü olan üye ülkeler Birliğin münhasır olmayan yetki alanlarından birinin çerçevesi içinde işbirliğine gidebilmektedirler. Güçlendirilmiş işbirliği, Anayasa tarafından getirilen bir yenilik olmasa da 
daha önce öngörüldüğünden farklı olarak yalnızca ortak dış ve güvenlik politikasıyla ve de emniyet güçleri ve ceza hukuku konularıyla sınırlandırılmamaktadır. Güçlendirilmiş işbirliğinde, oybirliğinden nitelikli çoğunluklu oy sistemine geçiş imkanı yaratıldığı gibi, olağan yasa yapma süreci de benimsenmektedir. Herhangi bir güçlendirilmiş işbirliği için daha önce gerekli olan en az sekiz üye ülke sayısı da bütün üye ülkelerin üçte birine değiştirilerek AB'nin son genişlemesiyle birlikte hem aynı asgarî ülke sayısı korunmuş, hem de geleceğe yönelik olası genişlemeler göz önüne alınmış olmaktadır.

\section{Sonuç}

İlk başlarda ortak bir Pazar ve ekonomik bir Topluluk oluşturmak için yola çıkan az sayıdaki Avrupa ülkesi zaman içinde genişleyerek siyasî bir birlik olmak için irade göstermişler fakat bir yandan da egemenlik sahalarının bazı bölümlerini Avrupa Birliğine devretmekte endişe duymuşlar, direnç göstermişlerdir. Bu nedenle yetki dağılımı konusunda AB'nin çok önemli bir çift kavramı olan "yerindenlik" ve "orantılılık" ilkelerini yaratmış ve Anayasa' ya eklenen 3üncui Protokol ile bu konunun gözetimini ulusal parlamentolara emanet etmişlerdir.

Anayasa'nın 20 Haziran 2003 tarihli ilk metninden sonra yapılan değişiklikler arasında Giriş'in en başında "motto" olarak yer alan Thucydides II, 37'den yapılan alınt1 da isabetli bir karar sonucunda çıkarılmıştır. Günümüzde çoğunluğun azınlığı ezmemesi ve onların da temsil edilerek haklarının gözetilmesi olarak yorumlanan demokrasi anlayışıyla pek de bağdaşmayan bir bakış açısı ortaya koyan ifade şuydu: "Anayasamızı...demokrasi olarak adlandınyoruz çünkü güç, bir azınlığın elinde olmayıp en geniş sayıya sahip olanların elindedir." Bu sözler, eleştiriler üzerine ${ }^{7}$ Anayasa Antlaşmasından çıkarılmıştır.

İlk metnin Giriş'inde yapılan bir başka değişiklik, ilk iki paragrafın birleștirilerek Avrupa'nın medeniyetinin ortak mirası olan kültür, din ve hümanizma kaynağından geldiğine yapılan vurgunun korunması olmuştur. İnsanın, temliki ve ferağı mümkün olmayan haklarının varlığı ve bunların temelindeki özgürlük, demokrasi eşitlik ifadeleri aynen yer aldığı gibi, akla saygının yerini hukukun üstünlüğü almış, Birliğin değerlerinin sıralandığı Madde 2'de yeni eklemelerle azınlıklara ait olan insanların haklarına ve kadın ile erkek arasında eşitliğe saygıya yer verilmiştir. Anayasa'da azınlıklara grup hakları değil de bireysel düzeyde bir azınlığa ait olma 
hakkının tanınması, Avrupa Konseyi'nin çerçeve anlaşmasındaki ifadeye yakın bir duruş alındığına dair dikkat edilecek bir husustur.

Anayasa hukukunun bütün üye ülkelerde eşit biçimde uygulanacağını belirten bir hükmün yer almasına da gerek duyulmuştur. Madde 5'e yapılan bir eklemeyle, Birlik nezdinde üye ülkeler arasındaki eşitlik vurgulanırken, her bir üye ülkenin ulusal kimliğinin ve toprak bütünlüğünün gözetileceği belirtilerek, hukukî düzenin ve ulusal güvenliğin korunacağı ve sürdürüleceği güvencesi verilmektedir. Birlik'ten ayrılmak isteyen bir üye ülkeye ilk kez böyle bir olanak tanıyan, birliğin değerlerini sürekli olarak çiğneyen bir üye ülkenin üyeliğinin de askıya alınabileceğini belirten Anayasa, getirdiği dayanışma hükmüyle, saldırıya uğrayan bir üye ülkeye diğer üye ülkelerin yardım elini uzatacağını da öngörmektedir.

\section{Summary}

The Treaty Establishing a Constitution for Europe has been designated as a positive step forward, having utmost importance. The text of the Cosntitution, as approved by the European Council at the summit meeting in Brussels on 17-18 June 2004 under the Irish Presidency, has now reached the stage when the member states enter into a period of ratification of the constitutional treaty according to their domestic laws so that the Constitution can go into effect.

After a 16-month period of negotiations conducted within the context of the Convention on the Future of the European Union, what are some of the new provisions having significant consequences for the future of the Union? The concept of "Christianity," as one of the subjects of debate, did not take place among the basic foundations forming the heritage of Europe; instead, a reference to cultural, religious and humanistic inheritance of Europe took precedence. The European values designated by the Constitution appeared as human dignity, freedom, democracy, equality, the rule of law and human rights, including the rights of persons belonging to minorities. The principles commonly shared by the member states were listed as pluralism, non-discrimination, tolerance, justice, solidarity and equality between women and men.

In addition to the statement that the Union shall be open to all European states which respect its values and are committed to promoting them 
together, the Constitution gives place for the first time to a provision on exit from the Union. In the case of a serious and persistent breach by a member state of the values of the Union, certain rights of the member state may be suspended. Any member state may also withdraw from the Union.

The use of Union competences, divided into three categories, is governed by the principles of referral, subsidiarity and proportionality. The provision on the Union law, expressing the primacy of Union law over the laws of the member states, has been moved into Title I, right before the provision on legal personality of the Union, as has been the provision on the symbols of the Union, the flag, the anthem, the motto ("united in diversity"), the currency euro and the Union day, May 9.

\section{Sonnotlar}

1 European Constitution, Official Journal of the European Union, C 310, Volume 47, 16 December 2004 (Notice No. 2004/C 310/01)

(http://www.europa.eu.int/scadplus/constitution/competences_en.htm)

2 En iyimser tahmine göre 2014 yılı ifade edilmektedir. Bkz. "Editorial Comments," 899-907, Common Market Law Review, Vol. 41, No. 4, August 2004, 904.

${ }^{3}$ Avrupa Kömür ve Çelik Birliği Kurucu Antlaşması (1951); Avrupa Topluluğu (Roma) Antlaşması (1957); Atom Enerjisi Topluluğu Kurucu Antlaşması EURATOM (1957); Maastricht Antlaşması (Treaty on the European Union) (1992).

${ }^{4}$ Birleşme Antlaşması (1965); Avrupa Tek Senedi (1986); Amsterdam Antlaşması (1997) (Yürürlük tarihi, 1999); Nice Antlaşması (2001) (Yürürlük tarihi, 1 Şubat 2003); yeni üye ülkelerle imzalanan antlaşmalar.

${ }^{5}$ Hauer Case, 44/79, Liselotte Hauer v. Länd Rheinland-Pfalz (1979) ECR 3, 727;

J. H. H. Weiler, The Constitution of Europe, Reprinted 2002, Cambridge University Press, 108, Footnote 7.

${ }^{6}$ Le Monde, 10 July 2004.

7 Anne Peters, "European Democracy after the 2003 Convention," 37-85, Common Market Law Review, Vol. 41, 2004, 37-38. 